\title{
O TEATRO ABOLICIONISTA DE APOLINÁRIO PORTO ALEGRE
}

Moacyr Flores

Encontramos no teatro abolicionista de Apolinário Porto Alegre princípios éticos abolicionistas que se chocam com os hábitos, virtudes, vícios e preconceitos raciais da sociedade porto-alegrense do século passado.

Analisaremos Benedito, comédia em um ato, porque tem como personagem um escravo no papel de gracioso, portanto simpático à platéia, pois provoca o riso ao escarmentar o vilão. Examinaremos também Os Filhos da Desgraça, onde Apolinário coloca ousadamente em cena os amores entre a senhora e o escravo, inaceitável na época. A solução final está de acordo com os princípios moralistas da sociedade porto-alegrense do século XIX.

$\mathrm{O}$ bibliófilo Júlio $\mathrm{H}$. Petersen teve a gentileza de colocar à nossa disposição os exemplares da revista do Partenon Literário, onde se encontram transcritas as citadas peças teatrais. A ele os nossos agradecimentos.

Apolinário Porto Alegre nasceu na cidade de Rio Grande, em 29 de agosto de 1844, filho de Antônio José Gomes Porto Alegre e de Delfina Joaquina da Costa Campelo. Seus ancestrais pelo lado materno eram de Lisboa, e dos Açores pelo paterno. Seu pai, tendo homônimo em Rio Grande, acrescentou Porto Alegre ao nome a fim de evitar confusões.

O pai, funcionário da fazenda, teve sua transferência para a Alfândega de Porto Alegre, no cargo de inspetor, onde chegou em 12 de outubro de 1859. Apolinário continuou seus estudos no colégio de seu parente Frederico Ferreira Gomes. Em 1861 matriculou-se na Faculdade de Direito de São Paulo. Sua mãe extremosa recomendou em carta a Apolinário para que ele cuidasse dos estudos e não lesse romances para não se atrasar.

Morrendo o pai, Apolinário retorna a Porto Alegre, onde se emprega como professor no colégio de Ciro José Pedrosa, tendo apenas 17 anos quando começou a sustentar a familia.

Em 1867, junto com seu irmão Aquiles, fundou o colégio Porto Alegre e em 1870, tendo como auxiliar o outro irmão, Apeles, instituiu o colégio Rio-Grandense.

Apolinário Porto Alegre, encarando a educação sob tríplice aspecto - físico, intelectual e moral -, não limitada exclusivamente ao ensino primário, resolveu com Hilário Ribeiro, no antigo Caminho do Meio, atual avenida Protásio Alves, num lugar fora da cidade, perto da atual rua Ramiro Barcelos, num prédio projetado especialmente, criar 
o Instituto Brasileiro, que durou 16 anos, reconhecido como o principal estabelecimento de ensino e como centro de propaganda republicana e abolicionista em pleno Império.

A morte levou sua filhinha América e quatro meses depois a sua esposa Elisa. Estes golpes inesperados fizeram com que fechasse o Instituto Brasileiro em 1891, reco. lhendo-se à Casa Branca, localizada no morro de Santana, no chamado rincão de São Francisco. A casa fôra quartel e hospital dos farroupilhas durante o cerco de Porto Alegre, cedida para tal fim por seu proprietário Estácio Bitencourt.

Apolinário comprou a casa em julho de 1885, reformando-a internamente, mas conservando-lhe a arquitetura. Organizou o pomar, um orquidiário e o jardim onde predominavam roseiras e trepadeiras. Olvidado do mundo, dedicou-se à leitura em francês, inglês, alemão e russo, elaborando seus originais sobre a revolução de 1835 e versos patrióticos ou líricos.

A revolução de 1893 atingiu a Casa Branca que foi invadida e saqueada, o governo republicano não satisfeito, abriu uma estrada em suas terras. Como havia pela imprensa, na atualidade, um movimento para tombamento do prédio histórico, seu proprietário tombou-o por terra, impedindo sua conservação e liberando o terreno para loteamento.

Apolinário esteve exilado em Desterro, hoje Florianópolis, de onde fugiu rocambolescamente para Montevidéu, regressando em 1895, quando já estava pacificado o Estado.

Os republicanos castilhistas emboscaram duas vezes Apolinário na estrada que ligava a Casa Branca a Porto Alegre, errando os tiros.

Recolhido a sua chácara dedicou-se inteiramente ao estudo e à literatura, esquecendo-se às vezes de alimentar-se.

A 23 de março de 1904, aos 59 anos de idade, morria Apolinário Porto Alegre na Santa Casa de Misericórdia, deixando uma vasta obra literária composta de estudos filológicos, de história, de política, de contos gauchescos, de romances regionalistas, de poesias, de ensaios e de teatro, esparsos na revista do Partenon Literário e nos jornais da época.

Algumas das obras teatrais de Apolinário Porto Alegre foram encenadas no teatro São Pedro, revertendo os fundos para compra de cartas de alforria de escravos. Seu teatro. como de todos os membros do Partenon Literário, era essencialmente romântico e portanto nacionalista, reproduzindo fatos, costumes e usos nossos.

Deixou-nos nove peças: $O$ Combate do Amazonas, ou $O$ Triunfo da Esquadr Brasileira, elogio dramático, representado em 17 de agosto de 1865 pela Associaç Artística do Teatro Sete de Setembro, de Rio Grande; Can e Jafet, drama levado à cerl pelos artistas amadores do Partenon Literário em 20 de dezembro de 1868; Sensitiv drama, Mulheres, comédia, publicadas em 1873 na revista do Partenon Literáni Benedito, esboço de uma comédia, em 1874; Os Filhos da Desgraça, em 1874, ambo publicados na revista do Partenon Literário; Vidal, peça cômica, montada em outubro 1875 pelos amadores do Partenon, no teatro São Pedro; Ladrōes de Honra, drama 1875; Epidemia Política, representada pela Sociedade Emancipadora Rio-Grandense, teatro São Pedro. ${ }^{1}$ 
A trama da comédia Benedito é bastante simples. Joaquim, ex-sacristão, 50 anos, obeso, beato e usurário quer casar com Marfisa, que tem apenas 18 anos, sendo a encarnação de toda a pureza e beleza que as mulheres possuem nesta idade, segundo os românticos. $\mathrm{O}$ vilão casadoiro quer emprestar dinheiro ao pai da heroína, Antônio, empregado público sem dinheiro, como soe acontecer. No entanto a bela Marfisa está apaixonada por seu primo Alfredo, tenente de infantaria, soberbo por seu porte marcial e enormes bigodes, um pouco estouvado mas dotado de caráter franco. Aí é que entra o moleque Benedito com suas travessuras, procurando ridicularizar o ex-sacristão Joaquim e proteger os interesses amorosos do tenente Alfredo, junto ao coração de Marfisa.

O cenário é bastante acanhado, como todas as casas de Porto Alegre em 1874: uma sala de mobílias simples, no fundo à esquerda uma porta que dá para um corredor; à direita duas janelas, portas laterais à vontade, sobrando assim pouca parede para os móveis. É a casa de Antônio, pai de Marfisa.

A comédia procura apenas divertir, sua temática é de que os jovens devem casar com os jovens e por livre escolha.

Na primeira cena Benedito põe a mesa para o almoço às 15 horas, quando Antônio deixava a repartição, pois naquela época o expediente era corrido das 9 às 15 horas. 0 comércio ficava aberto das 8 às 20 horas. Benedito não agüenta mais de fome e belisca 0 prato de azeitona.

0 vilão entra pelos fundos, cumprimentando:

Joaquim - Louvado seja Deus e a Virgem Santíssima nesta casa.

Joaquim é cheio de expressões como: "Por São Tiago, Graças à Santíssima Trindade, pela Virgem Santíssima". Enquanto caminha em cena, monologando que casará com Marfisa porque emprestará dinheiro ao seu pai, o moleque Benedito caminha atrás, imitando os gestos e colocando-lhe um rabo de papel. O sacristão descobre e quer bater-the, o negrinho corre em volta da mesa e de propósito derruba os pratos no chão. Marfisa entra em cena e pede explicações. Joaquim não consegue falar por cansaço de correr atrás do moleque. Este conta que Joaquim quis lhe bater porque ele teria entrado em seu quintal para roubar frutas. Marfisa não acredita nas mentiras do negrinho, que sai de cena chorando.

Marfisa conversa com Joaquim. A sinhazinha considera o moleque incorrigível e quer vendê-lo na primeira oportunidade. Joaquim conta-lhe que já arranjou o casamento com ela. A moça surpresa, responde:

Marfisa - Então pretende-me?

Joaquim - Amo-a Marfisinha.

Marfisa - (grave) Senhor Joaquim, dê-se ao respeito. Cinqüenta anos são a idade do juízo.

Joaquim - $\mathrm{O}$ casamento, o amor não são uma loucura? Virgem Santíssima.

Marfisa - São uma loucura, quando há a disparidade de condição e de idade.

Marfisa confessa que desde criança entregou seu coração ao primo Alfredo que luta guerra contra o Paraguai. 
Desprezado, Joaquim jura vingança. Benedito da janela dirige gracejos ao velhote obeso que se retira. $\mathrm{O}$ moleque vê um tenente que se aproxima pela rua, grita por Marfisa e dispara ao encontro do militar. Marfisa, que não entende a alegria do escravo, reclama por sua atitude:

Marfisa - Não sei quando meu pai há de livrar-se deste maldito crioulo.

Crioulo era o negro nascido no Brasil. O que vinha da África chamava-se de nação, às vezes com referências étnicas como de nação mina, nação gege, ou nação cabinda.

Benedito entra com Alfredo pela mão. Os dois primos se encontram. O tenente usa expressões como inferno, mil bombas e diabo, fazendo com que Marfisa lhe solicite para deixar tal linguagem militar. A moça entra para preparar uma limonada. Benedito esgrime com a espada de Alfredo e depois conta as intenções do Joaquim. O militar jura que irá cortar-the as orelhas. Alfredo sai para buscar sua bagagem, solicitando que a prima não revele sua presença.

Joaquim pede a Antônio os dois contos que lhe emprestou. $\mathrm{O}$ pai de Marfisa diz que não tem o dinheiro e que com o casamento tudo se arranjará. Joaquim quer desfazer 0 casamento porque Marfisa se comprometeu com o primo. 0 pai retruca, seguindo 0 patriarcalismo reinante:
Antônio - Em minha casa sou o soberano senhor, e Marfisa não tem outra vontade que a de seu pai.

Joaquim apresenta-se como covarde, com medo de Alfredo, mas coloca nele todos os defeitos atribuídos aos soldados, que na época eram maus elementos, por se considerar o exército como um corretivo a todos os males sociais.

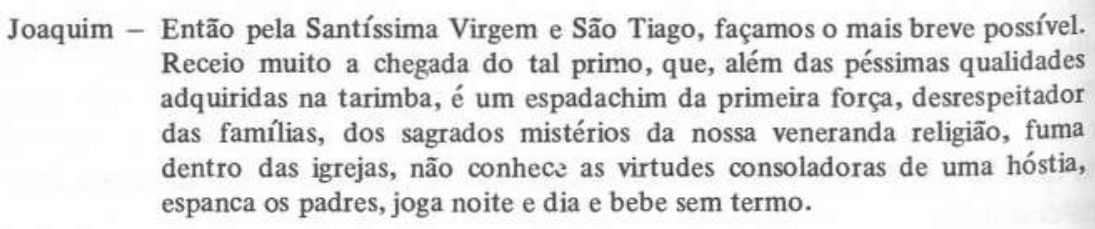

$\mathrm{O}$ casamento é marcado para o dia seguinte. Joaquim pede para castigar Benedito que the colocou um rabo de papel às costas. Antônio chama o moleque e entrega a palmatória a Joaquim. O negrinho não tem o direito de se defender. Entra Alfredo e impede o castigo. Enquanto o sacristão apela para tudo quanto é santo, o tenente esbraveja com Satanás, Inferno e Bombas. O Joaquim quer sair, mas Alfredo obriga-0 a ficar. Benedito dá um jeito de avisar o assustado Joaquim que o tenente quer lhe cortar as orelhas.

$\mathrm{O}$ jantar se passa com Alfredo falando e ameaçando, dizendo que arrancou orelhas de 87 e meio paraguaios e quer dar uma demonstração, como se Joaquim fosse um paraguaio. O velhote foge de medo. Antônio se desespera porque Joaquim é seu credor e receia uma vingança. Alfredo revela que recebeu uma herança, velho chavão do teatri romântico, e pede a mão de Marfisa. A felicidade estende-se também a Benedito, que pede 
para ser soldado. Alfredo promete-lhe que ele sentará praça e servirá em sua companhia. Cai o Pano.

O negro que sentasse praça no exército, por ordem de seu amo, recebia liberdade enquanto servisse como soldado. Como os rio-grandenses não queriam servir na infantaria, por considerarem a cavalaria a arma mais nobre, aquela era destinada a ser preenchida por negros ou por brasileiros de outras províncias. Os farroupilhas também utilizaram escravos infantaria, tornando-os libertos enquanto prestassem serviço, conforme o uso do Império Brasileiro. Depois, o tratado de paz reconheceu esta situação.

Na peça não há um retrato da situação do escravo na sociedade brasileira, fora alguns apartes do Benedito, como:

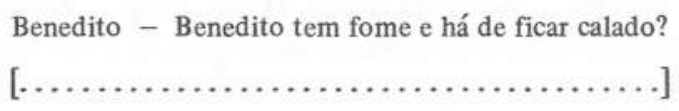

Benedito - Só o pobre Benedito não pode sentar-se.

O castigo da palmatória, que seria aplicado injustamente, é o único elemento que comoveria os espectadores abolicionistas. A peça é tímida, não protesta e nem contesta. Diverte e quer educar com o seu tema.

Os Filhos da Desgraça é um drama popular com um prólogo e quatro atos. A ação passa-se na Bahia, iniciando em 1856, durante o surto de cólera e terminando em 1868.

A apresentação da peça foi proibida pela polícia porque coloca em evidência os amores de uma senhora branca com seu escravo mulato. 0 tema da peça procura moralizar o povo, mostrando "o contato pernicioso e tão abusado entre nós dos escravos com pessoas de uma família" 2

Com tal temática, Apolinário não poderia colocar a ação em Porto Alegre, porque provocaria a revolta de muitos chefes de família.

Antônio José Gonçalves Chaves, em suas memórias de 1822, dedicou um capítulo à escravidão, demonstrando que o trabalho escravo era menos produtivo que o assalariado e que a promiscuidade entre senhores e escravos trazia danos morais às famílias. ${ }^{3}$

Os Filhos da Desgraça, para os gostos atuais, é um dramalhão, mas possivelmente fez chorar os leitores da revista do Partenon Literário, pois possuía todos os ingredientes do teatro romântico: a criança abandonada com medalha no peito, o amor contrariado, as diferenças de classes sociais, o salvador que arrisca a vida para deter o cavalo em galope furioso e que se lança ao mar para salvar uma criança, os maus completamente maldosos, os bons terrivelmente bons, a força do dinheiro, o final feliz com prêmio aos bons e castigo aos maus.

A intriga tem melhor urdidura que a comédia Benedito, mantendo o interesse do leitor. Basílio é a personificação do mal, completamente mau, inteiramente mau. Tem seus olhos voltados para o dinheiro e para sua única filha, Carlota, moça mimada e estragada pelos maus exemplos do pai. Basílio não titubeia em protestar hipotecas, cobrar dívidas de viúvas e órfãos, trair o sócio e mandar assassinar seu filho de criação para manter a fortuna. 
O prólogo inicia com Basílio contratando a morte de seu filho adotivo, Fábio, com o marinheiro André. O moço deverá ser lançado no meio do oceano. Sai André e Basílio se recrimina por ter recolhido o menino em sua porta, agora terá que matar para evitar futuros aborrecimentos. Entra Fábio que chama Basílio de pai, este não gosta do tratamento. Comunica que o jovem irá para Hamburgo a fim de trabalhar no comércio e enriquecer. Basílio se retira e entra a mulata Luiza, amante de Fábio, que conta a este que esmolou na rua para comprar a alforria de Gabriel, filhinho de ambos. Os amantes se despedem. Quando fica só, Fábio reconhece sua fraqueza em não querer sofrer a desonra, dando nome ao filho. Luiza já havia comprado sua alforria, pagando a Basilio a importância de dois contos de réis, valor altíssimo, pois na época a alforria custava cerca de um conto de réis.

Depois Basílio recebe a visita da viúva Maria, com a filha menor Carolina. 0 usurário acaricia a menina, galanteia a viúva, mas quando esta the pede dinheiro para salvar-se da miséria, Basílio torna-se grosseiro e insulta as duas, terminando por comprar as jóias, por preço ínfimo, que a viúva vende para salvar-se da miséria. A cena corresponde aos padrōes do romantismo:

\section{Maria - Dê-mos senhor. (Basílio reúne as jóias, vai à secretária no fundo e começa a contar dinheiro) Meu Deus, que mal fizemos nós? Ontem tanta felicidade e hoje tantos infortúnios! Adeus! Adeus! Meu caro Antônio, perdoa-me... Se vim vendê-las é que seu produto vai salvar a mim e a tua filha da fome e da miséria.}

A seguir entra a mulata Luiza suplicando que seu filho seja liberto. Entrega 0 dinheiro que esmolou a Basilio, este escreve a carta de alforria, a mulata cai fulminada pela cólera-morbus, Basílio rasga o documento e embolsa o dinheiro, terminando o prólogo.

O primeiro ato passa-se 12 anos depois, na casa da viúva Maria, que costura com sua filha Carolina, tendo como única consolação o trabalho. As duas falam de Fábio e o rapaz logo entra, interroga sobre a mulata Luiza e seu filho Gabriel, que ninguém sabe onde se encontra.

Um criado vem chamar Maria para que vá provar os vestidos em sua senhora, pois as mulheres elegantes não saiam de casa para fazerem compras, mandavam um escravo buscar as fazendas nas lojas para escolherem em casa.

Fábio e Carolina trocam confidências, ela diz que sabe do noivado dele com Carlota, a filha de Basílio. O rapaz confessa que tem medo de casar com Carlota, porque ela é muito geniosa. Comunica que ela deseja ver Carolina.

Depois que Fábio se retira, entra Carlota que procura humilhar Carolina. A mọ̧a responde à altura e Carlota jura vingar-se, pois aquela casa the pertence.

$\mathrm{O}$ segundo ato tem por cenário o armazém de Basílio, no fundo, três portas por onde se vê forjas e operários. Os operários trabalham e cantam enquanto malham as bigornas, numa imitação ao coro dos Ferreiros da ópera $I l$ Trovatore, de Verdi. Basilio não concorda com estas inovações entre os operários que podem the trazer algum prejuízo. Fábio é o responsável por estas mudanças no trabalho dos operários. Basílio instrui seu procurador Teodósio para que execute dívidas e hipotecas. Este previne ${ }^{0}$ 
usurário contra a vingança de pessoas inocentes, que podem tomar a justiça em suas mãos. Basilio quer contratar um escritor para difamar o ferreiro que the venceu concorrências para fornecimento de ferro. Exige que sejam despejadas Maria e Carolina, degradando a esta. Teodósio recusa-se a fazer tal coisa porque tem família e filhos. Pede notícias de um tal de Adriano, que foi preso em Desterro (hoje Florianópolis). Teodósio explica que Adriano foi encarcerado por 28 anos, por roubo, retornando em 1860, velho e alquebrado, para o Rio de Janeiro.

Basílio declama seu monólogo, citando Adriano e seu filho como os únicos pesadelos que tem. Entra Carlota repreendendo o pai, por querer levar o escravo Armínio para o engenho. Ela o quer de boleeiro. Pede ao pai novas parelhas de cavalos. Basílio faz todas as vontades da filha, que age com dureza com seu pai. Quando ela se retira, Basílio toma a resoluçãc de fazer desaparecer Armínio, porque Carlota não sabe quem ele é realmente.

A cena escurece. Entram Fábio e Carolina. Ele encontrou-a presa por uma patrulha de soldados porque a moça esmolava na rua depois do toque de recolher. Ela conta que sua mãe Maria encontra-se à morte e com ameaça de despejo. Ouvem um barulho, escondem-se atrás de uma caixa. Entra Armínio temeroso e logo após Carlota. Escravo e senhora se encontram numa cena amorosa que segue os cânones do romantismo, mas que fere a moral por ser entre a senhora e o escravo mulato:

Carlota - Porque te amo muito, Armínio! Ó este amor foi uma verdadeira desgraça para ambos.

Ela conta que se apaixonou pelo escravo quando ele a salvou do cavalo que disparava a galope. Sentiu este amor crescer quando ele salvou uma criança que se afogava no mar, enquanto pessoas olhavam temerosas. Carlota - E o amor que te voto, se me avilta diante dos homens, engrandece-me aos
olhos de Deus.

A deixa de Carlota encerra a temática da peça, que defende a tese de que o contato com os escravos degrada as pessoas da família. Esta idéia fazia parte do consenso geral, sendo utilizada como argumento pelos abolicionistas.

Armínio pergunta por seu casamento com Fábio. Carlota responde que é apenas uma comédia e solta uma gargalhada. Fábio não se contém e avança armado de punhal. Basilio acordado pelos gritos, chega ao armazém. Fábio apresenta Carlota como amásia de Armínio. Basílio cai em desespero, considerando que foi um pai desnaturado, envergonhado com as relações entre o escravo e a filha.

$\mathrm{O}$ terceiro ato passa-se num cárcere. É noite, uma lâmpada arde suspensa no muro. No fundo há uma bilha. Uma porta à esquerda.

Adriano está preso junto com Armínio que tem a camisa rasgada e ensangüentada. Adriano pensa alto no infame que lhe roubou a fortuna, matou sua esposa e roubou-lhe o filho. Armínio delira com febre, gritando seu amor por Carlota, convidando-a para fugirem para o sertão. Adriano não se contém, fazendo apologia à libertação: 
Adriano - Eis uma nova vítima dos homens! Escravo, sujeita-te ao látego, és propriedade, não podes erguer a voz contra teu senhor. Porém, tão moço, tão belo, qual será teu crime? ... Se o não tens, de certo inventarão um, os homens são capazes de tudo.

Entra o carcereiro e conta que o escravo foi acusado de furto, mas que na realidade está sendo castigado por Basílio Sepúlveda, por querer amar sua fillha. Adriano se revolta com a injustiça, o carcereiro, homem simples, responde filosoficamente:

\section{Carcereiro - Que se há de fazer-se? É ordem do mundo; e demais é o senhor que manda castigar o que the pertence.}

O carcereiro avisa que está lá embaixo um moço interessado na sorte de Armínio e que deixará a porta aberta para que Adriano possa chamar no caso do escravo piorar. Adriano tenta minorar os sofrimentos de Armínio e encontra uma pequena cruz no pescoço do escravo, era a cruz de seu filho Fábio, como sempre acontece nos dramas românticos. Desperta Armínio e quer saber quem lhe deu a cruz. Fábio, que assistiu a cena da porta, abraça Armínio, pois este é seu filho Gabriel, filho da desgraçada Luiza. Carlota que também presenciou a cena, enxugando com a manga do casaco uma lágrima que the vem nos olhos, exclama:

\section{Carlota - Altos mistérios de Deus!}

O que na realidade é apenas um chavão do romantismo.

Cai o pano neste curto e melodramático terceiro ato.

O quarto ato é na sala da casa da viúva Maria, onde Adriano conta a seu filho Fábio como foi roubado pelo infame Basílio, terminando na prisão acusado de falsário e ladrão. Adriano vai buscar o pobre Gabriel que está com um dos pulmões afetado pelo bárbaro espancamento.

Chega Carolina e Fábio declara seu amor, a moça protesta comovida porque ele é rico e ela é pobre. Fábio sai e entra Basílio assustado, pedindo que Carolina lhe permita descansar. Entra Carlota e acusa o pai de sua desgraça:

Carlota - Sim, a infame Carlota, que vem dizer-te: ri-te, Carolina, ante meu opróbrio, ri-te, regosija-te, venceste, porque aquele velho imbecil (designa a Basílio) apontou-me as veredas do vício, em vez de guiar-me à virtude.

Carolina, a encarnação perfeita do bem e da virtude, lança-se nos braços de Carlota, suplicando que ela perdoe seu pai. $O$ velho se arrasta pelo chão, suplicando perdão:

Carlota - (Delirante) Perdoá-lo? Quem perdoará as minhas faltas? Piedade? Ah! Isto é irrisório! Quem a terá por mim? Nunca! Nunca! Resta-me morrer, meu opróbrio todos o sabem hoje, sou odiada, nem dão-me o olhar de compaixão que merece qualquer ente desprezível! (A Basílio) Maldição. (Sai e logo depois se ouve o rodar de um carro que se afasta.)

Baślio pensa que delira, Carolina, boa moça, tenta consolar. Basílio crê que é um fantasma quando entra Adriano. Este quer matar o infame. Carolina impede. Basilio 
oferece dinheiro. Adriano recusa com altivez e manda que ele suma de seus olhos. Basílio corre e esbarra em André, o marujo que deveria ter matado Fábio em alto mar e que terminou numa prisão por seu intento que falhou, acusado por testemunhas. Agora também quer se vingar. Como Adriano perdoou, depois de injustamente ter passado 28 anos de prisão, e André que só esteve preso dez anos, só resta soltar Basílio que desmaia.

Fábio trás uma funesta notícia:

Fábio - Morreu. .. Fiz tudo por salvá-la... não o quis.

Todos - Quem?

Fábio - Carlota. . . O castigo dos céus tardou, mas veio sempre... A casa de Basílio é toda chamas...

Termina o drama com uma exortação de Adriano:

Adriano - (Apontando para o céu, a Carolina e Fábio) Deus, meus filhos, seja a única luz que ilumine a nova senda que vão trilhar.

Os Filhos da Desgraça é um drama contestatório ao sistema escravocrata, muito mais vibrante que a comédia Benedito. $\mathrm{O}$ fato de o senhorzinho branco ter escrava como amante era aceito pela sociedade, a criança era considerada como cria de casa e batizada pelo próprio pai. Mesmo assim os preconceitos de Fábio não permitem que ele reconheça seu filho com a mulata Luiza, uma liberta. Carlota, amante de um escravo mulato, não ousa enfrentar as pessoas e foge através do suicídio. Apolinário Porto Alegre deu a sua peça um final feliz, onde não incluiu o mulato Gabriel e sua amásia Carlota. Preferindo que ela se suicidasse, salvando assim as convenções sociais que não admitiam relações entre escravo e senhora.

O drama Os Filhos da Desgraça está inserido na filosofia dos abolicionistas que por princípios éticos, além dos econômicos, não admitem a escravidão e também que os libertos participem da vida social em comum.

Em 1884, quando os membros do Partenon Literário desenvolveram a campanha de libertação dos escravos, batendo de porta em porta para que os senhores concedessem a liberdade, reuniram os libertos na Várzea, chamada por este fato de Redenção e atualmente de Parque Farroupilha, dando por finda a missão abolicionista. Os negros ergueram seus barracos na Colônia Africana e permaneceram marginalizados na estrutura social. Depois, em 13 de maio de 1888 repetiu-se o crime social, os escravos foram libertados sem indenização, sem instruçбes e sem meios de sobrevivência.

\author{
Departamento de História \\ Pontifícia Universidade Católica \\ do Rio Grande do Sul \\ Porto Alegre - Brasil
}




\section{NOTAS}

${ }^{1}$ VILlAS-BOAS, Pedro Leite. Notas de Bibliografia Sul-Rio-Grandense. Porto Alegre, A Nação-SEC, 1974, p.392-4.

${ }^{2}$ SILVA, Hilário Ribeiro A. e. Ementário mensal. In Revista do Partenon Literário, Porto Alegre, 1(4):133-142, junho de 1869, p.140.

${ }^{3}$ CHAVES, Antônio José Gonçalves. Memórias Economo-Políticas. In Revista do Instituto Histórico e Geográfico do Rio Grande do Sul, Porto Alegre, II e III trimestre, 1922.

\section{BIBLIOGRAFIA}

1. CLEMENTE, Elvo. Apolinário Porto Alegre. Revista Veritas, Porto Alegre, PUC, 1(1): 13-25, novembro, 1955.

2. LANONE, Carlos Alberto. in prefácio de $O$ Vaqueano, de Apolinário Porto Alegre, São Paulo, ed. Três, 1973.

3. HESSEL, Lothar e outros. O Partenon Literário e sua Obra.Porto Alegre, Flama/SEC, 1975.

4. PORTO ALEGRE, Álvaro. A polinário Porto Alegre. Porto Alegre, Thurmann, 1954.

5. PORTO ALEGRE, Álvaro. O ciclo de A polinário Porto Alegre. Porto Alegre, Thurmann, 1944.

6. PORTO ALEGRE, Álvaro. Ronda da História. Porto Alegre, Thurmann, 1956.

7. PORTO ALEGRE, Álvaro. Partenon Literário. Porto Alegre, Thurmann, 1962.

8. PORTO ALEGRE, Aquiles. Através do passado. Porto Alegre, Globo, 1920.

9. REVISTAS do Partenon Literário. Coleção particular de Júlio H. Petersen. 